\title{
Comparison of "Look-Alike" Implant Prosthetic Retaining Screws
}

\author{
Merle J.Jaarda, DDS, MS, * Michael E. Razzoog, DDS, MS, MPH, $\dagger$ \\ and David G. Gratton, BS $¥$
}

\begin{abstract}
Purpose: The maximum preload torque of implant prosthetic retaining screws from four manufacturers and of two alloy types was measured to determine one index of interchangeability of intersystem components.

Materials and Methods: Implant prosthetic retaining screws from four manufacturers (3i Implant Innovations Inc, West Palm Beach, FL; Impla-Med Inc, Sunrise, FL; Nobelpharma USA Inc, Chicago, IL; and Implant Support Systems Inc, Irvine, CA) and of two metal types (gold and titanium) were investigated using an in vitro simulation model. Five screws of each type were tightened down against a gold cylinder using a Tohnichi BTG-6 torque gauge (Tohnichi American Corporation, Northbrook, IL) until fracture occurred.

Results: The 3i Implant Innovations gold and the Nobelpharma gold were not significantly different. The 3i Implant Innovations titanium and the Impla-Med gold were able to withstand less preload torque than the 3i Implant Innovations gold and the Nobelpharma gold. The Implant Support Systems titanium was able to withstand significantly more preload torque than all of the other screws.

Conc/usions: Interchanging implant prosthetic retaining screws could introduce new and unknown variables that may affect the long-term survival of implant fixtures and/or the implant prostheses.
\end{abstract}

J Prosthod 1995;4:23-27. Copyright 1995 by the American College of Prosthodontists.

INDEX WORDS: implant components, torque, ultimate torque / tensile strength, preload

$I^{N}$ N THE LAST DECADE, the introduction of implant hardware that is supposed to be interchangeable between systems has caused the dental profession to question the efficacy of using these "look-alike"] components. Although there are rigid written specifications for screws and fasteners used in industry, there are none for those used in the health-care field. It is reasonable that the profession requires the standardization and specifications of these components. This most important question was the topic of a "Current Issues Forum" in the International Journal of Oral and Maxillofacial Implants. ${ }^{1}$ The consensus of the forum participants was that there is a need for long-term clinical trials to provide "scientific proof" regarding the long-term survival of

From the University of Michigan, School of Dentisim, Ann Arbor, MI.

* Assistant Professar, Department of Prosthodontics.

tAsinciate Professor, Department of Prasthodontics.

†Department of Prosthodontics.

Supported by USPHS grant DE07101.

Correspondence to: Merle.J. Jaarda, DDS, MS, Department of Prosthodontics, University of Michigan, School of Dentistry, Ann Arber, MI 48109-1078.

Copyright 01995 by the Amenican College of Prosthodontists 1059-941X/95/0401-0006\$5.0010 these "look-alike" components. All panelists agreed that the success of these components depends on their accuracy and precision of fit, along with the mechanical and physical properties. Historically, dental implant research has concentrated on the intraosseous implant fixture; however, the literature is expanding regarding the importance of the prosthetic components in long-term implant success. While the dental profession waits for clinical trials, practitioners must rely on their clinical judgment to evaluate the accuracy and precision of the fit of these components. Unfortunately, the clinician has no practical mechanism to evaluate the mechanical and physical properties because, unlike many other areas of dentistry where specifications have been defined, there are no written specifications for prosthetic implant components. Most information regarding specifications of implant fixtures and their prosthetic components is proprietary and difficult to interpret even when it is available.

The purpose of this project was to measure the maximum preload torque of implant prosthetic retaining screws from four manufacturers and of two alloy types to determine one measure of interchange ability of intersystem components. 


\section{The Problem: Preload Theory}

Within the last 4 years, several implant manufacturers introduced the concept of preloading implant components. Preloading of components does not seem to be a concept based on published research in the implant field nor a response to a particularly great problem. A recent study showed that manual tightening of implant prosthetic retaining screws was inconsistent in regards to intraoperator and interoperator variance. ${ }^{2}$ That finding, combined with the assumption that the vast majority of implantretained prostheses functioning today have been placed with only manual tightening of the retaining screws, should cause the clinician who is concerned about preloading components to question whether these prostheses should be recalled and the retaining screws optimally tightened.

Adding to the controversy are the "look-alike"। implant components that have become available that leave the clinician with the question of what constitutes proper preload torque appropriate for each of these components. These "look-alike" components are generally fabricated from gold or titanium alloys and include no written specifications regarding mechanical or physical properties other than the statement that they are compatible with the components of the original system.

The practitioner must remember that the original preload torque recommendation of $10 \mathrm{Ncm}$ for the gold implant prosthetic retaining screw was based on the fact that with a preload of the abutment/ abutment screw/prosthetic cylinder/prosthetic retaining screw complex of $10 \mathrm{Ncm}$, the "combined screw stress from tension and shear was just below the yield strength of the material.".3 If the alloy of these "look-alike" components no longer is the same as the original or if the tolerances are different, is the $10-\mathrm{Ncm}$ preload still applicable?

The problem has become more complex as some research suggests that the Nobelpharma gold implant prosthetic retaining screws (Nobelpharma USA Inc, Chicago, IL) be preloaded to $12.4-\mathrm{Ncm}$ torque, ${ }^{4}$ whereas the manufacturer has suggested $10 \mathrm{Ncm} .^{5}$

\section{Materials and Methods}

"Look-alike" implant prosthetic retaining screws were selected from three manufacturers and two alloy types (Table 1), and the Brånemark gold implant prosthetic retaining screws (Nobelpharma USA Inc) were used as the control. All "look-alike" screws were stated in the manufacturers' marketing material to be compatible with the
Table 1. The "Look-Alike" Implant Prosthetic Retaining Screws Tested According to Manufacturers' Alloy Type.

\begin{tabular}{ll}
\hline \multicolumn{1}{c}{ Manufacturer } & \multicolumn{1}{c}{ Alloy } \\
\hline Nobelpharma USA Inc, Chicago, IL & Gold \\
3i Implant Innovations Inc, West Palm & \\
Beach, FL & Gold \\
Impla-Med Inc, Sunrise, FL & Gold \\
3i Implant Innovations Inc, West Palm & \\
Beach, FL. & Titanium \\
Implant, Support Systems Inc, Irvine, CA & Titanium \\
\hline
\end{tabular}

Nobelpharma gold implant prosthetic retaining screws. All of the tested screws used in this study were of the slotted-head type.

An in vitro model (Fig l) was fabricated simulating the usual clinical application of gold implant prosthetic retaining screws. Five screws of each type were tightened down against a Nobelpharma gold cylinder using a Tohnichi B'TG-6 torque gauge (Tohnichi American Corporation, Northbrook, IL) until fracture of the gold screw occurred.

\section{Results}

The torque at which ultimate fracture occurred is shown in Table 2. A Duncan Multiple Range (significance level, .05) test was performed on the data (Table 3). Three statistically different groups based on the torque data became separated from the analysis of the data. The gold screws from Nobelpharma USA and 3 i Implant Innovations (West Palm Beach, FL) were not significantly different from each other but were different from the other screws. The Impla-Med gold (Impla-Med Inc, Sunrise, FL) and the $3 i$ Implant Innovations titanium screws were not significantly different from each other; however, they were able to withstand significantly less preload torque than the gold screws from Nobelpharma USA and $3 \mathrm{i}$ Implant Innovations, as well as the titanium screws from Implant Support Systems Inc (Irvine, CA). The titanium screws from Implant Support Systems were able to withstand significantly more preload torque than all the other screws.

\section{Discussion}

In comparing the results of the present study with other research and recommendations, it is important for the practitioner to critically compare testing methodologies. Many types of physical tests can be used to evaluate the torque-tensile strength of screws and fasteners. One common test is a torsional test in which the tip of a screw is clamped into a holding 


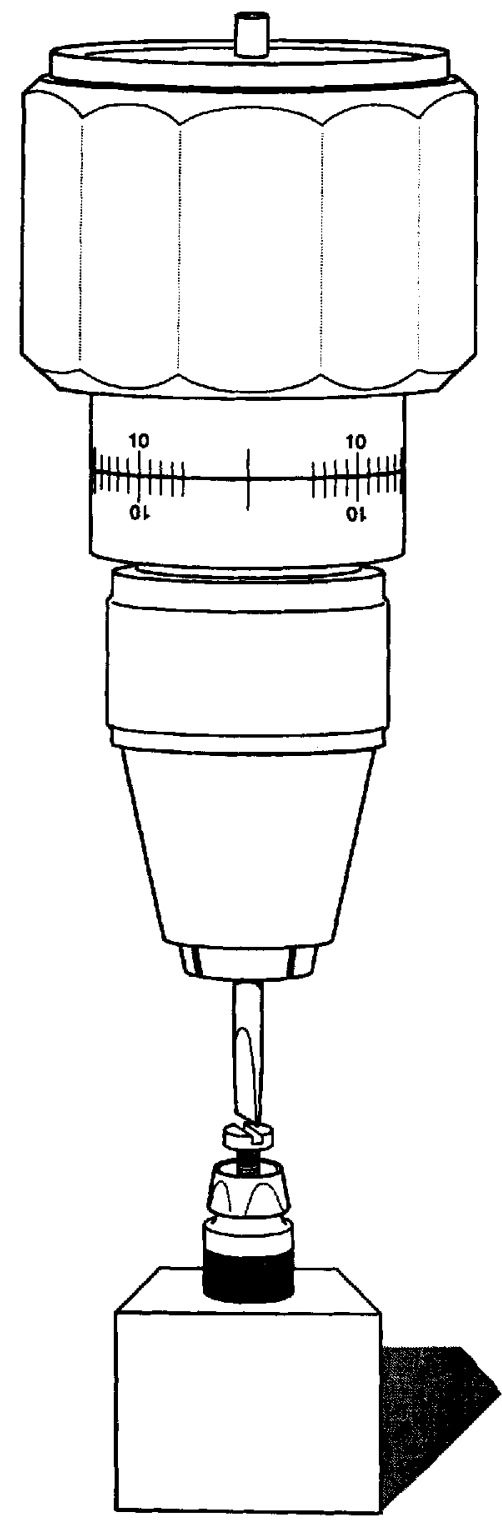

Figure 1. Diagram of the in vitro model and Tohnichi BTG-6 gauge used to apply the torsional load.

device, and a torque load is applied to the head of the screw (Fig 2). A second method is a torque-tensile test in which the screw being studied is used to clamp two materials together. In this case, the screw is inserted through a hole in one material and then into a threaded receptacle in the second material. $A$ torque load is then applied to the head of the screw in a manner consistent with the screws ultimate application (Fig 3). Both techniques are valid test methodologies, although the dentist who will use the information derived from the test should be cautioned that they are measuring greatly different phenomena. In
Table 2. The Mean Ultimate Torque Values and SDs

\begin{tabular}{llll}
\hline & & \multicolumn{2}{c}{$\begin{array}{c}\text { Torque } \\
(N c m)\end{array}$} \\
\cline { 3 - 4 } \multicolumn{1}{c}{ Manufacturer } & Alloy & Mean & $S D$ \\
\hline Nobelpharma USA & Gold & 24.5 & 1.66 \\
3i Implant Innovations & Gold & 24.4 & 3.42 \\
Impla-Med & Gold & 20.7 & 1.72 \\
3i Implant Innovations & Titanium & 20.1 & 1.34 \\
Implant Support Systems & Titanium & 35.2 & 3.42 \\
\hline
\end{tabular}

the present study, the latter methodology was used in an attcmpt to simulate the clinical application.

To understand the events occurring within the screws being studied, it may be helpful to refer to a typical stress/strain diagram ${ }^{6}$ (Fig 4). Any screw begins to deform as the load is applied, which is represented by the OP line segment of the graph. In this portion of the stress and strain curve, there is a straight-line relationship between the stress and the strain. The initial deformation is elastic, which means that if the load is removed, the screw will return to its original form. The point $\mathrm{E}$ at which permanent deformation occurs is called the elastic limit. As the load is increased, the stress and strain relationship will no longer be a straight-line relationship, and the line will begin to curve. The point $P$ at which the line

Table 3. The Duncan Multiple Range Test Values

\begin{tabular}{|c|c|c|c|}
\hline Screae & Comparison Screw & Difference & $\begin{array}{c}\text { Critical } \\
\text { Difference }\end{array}$ \\
\hline \multirow{4}{*}{$\begin{array}{l}\text { 3i Implant Inno- } \\
\text { vations tita- } \\
\text { nium }\end{array}$} & Impla-Med gold & .600 & 3.278 \\
\hline & $\begin{array}{l}3 i \text { Implant Inno- } \\
\text { vations gold }\end{array}$ & 4.300 & $3.445^{*}$ \\
\hline & $\begin{array}{l}\text { Nobelpharma } \\
\text { USA gold }\end{array}$ & 4.400 & $3.534^{*}$ \\
\hline & $\begin{array}{l}\text { Implant Sup- } \\
\text { port Systems } \\
\text { titanium }\end{array}$ & $\mathrm{I} 5.100$ & $3.612^{*}$ \\
\hline \multirow[t]{3}{*}{ Impla-Med gold } & $\begin{array}{l}3 i \text { Implant Inno- } \\
\text { vations gold }\end{array}$ & 3.700 & $3.278 *$ \\
\hline & $\begin{array}{l}\text { Nobelpharma } \\
\text { USA gold }\end{array}$ & 3.800 & $3.445^{*}$ \\
\hline & $\begin{array}{l}\text { Implant Sup- } \\
\text { port Systems } \\
\text { titanium }\end{array}$ & 14.500 & $3.534^{*}$ \\
\hline \multirow{2}{*}{$\begin{array}{l}\text { 3i Implant Inno- } \\
\text { vations gold }\end{array}$} & Nobelpharma & .100 & 3.278 \\
\hline & $\begin{array}{l}\text { USA gold } \\
\text { Implant Sup- } \\
\text { port Systems } \\
\text { titanium }\end{array}$ & 10.800 & $3.445^{*}$ \\
\hline $\begin{array}{l}\text { Nobelpharma } \\
\text { USA gold }\end{array}$ & $\begin{array}{l}\text { Implant Sup- } \\
\text { port Systems } \\
\text { titanium }\end{array}$ & 10.700 & $3.278 *$ \\
\hline
\end{tabular}

*Significant at .05 level. 


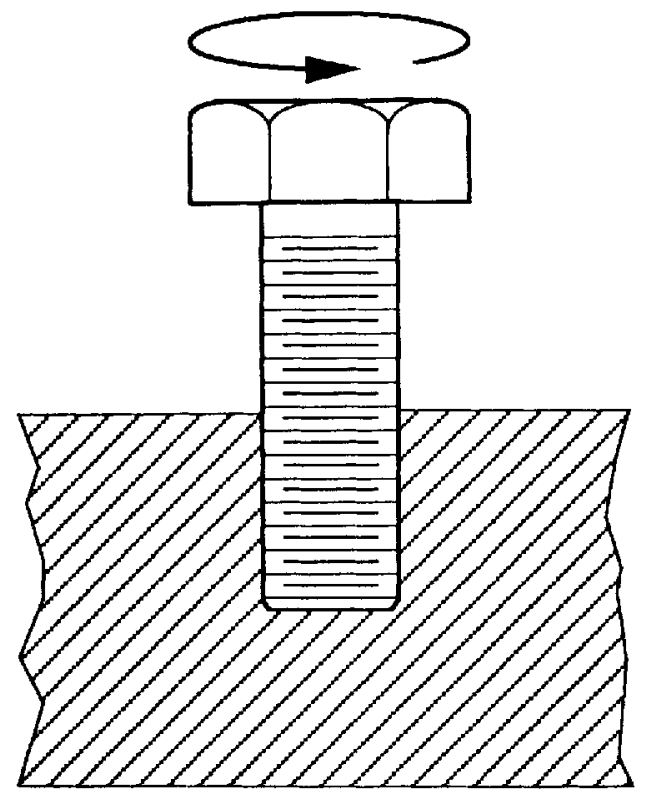

Figure 2. An example of a torsional load caused by torque applied to the head of the bolt.

begins to curve is called the proportional limit. During the testing of the screw, there is a point $\mathrm{Y}$ at which the strain begins to increase rapidly without a corresponding increase in stress. This point on the stress and strain graph is called the yield point; however, the yield point is not obvious in the stress and strain diagrams of many dental materials. Eventually the stress within the system reaches its maxi-

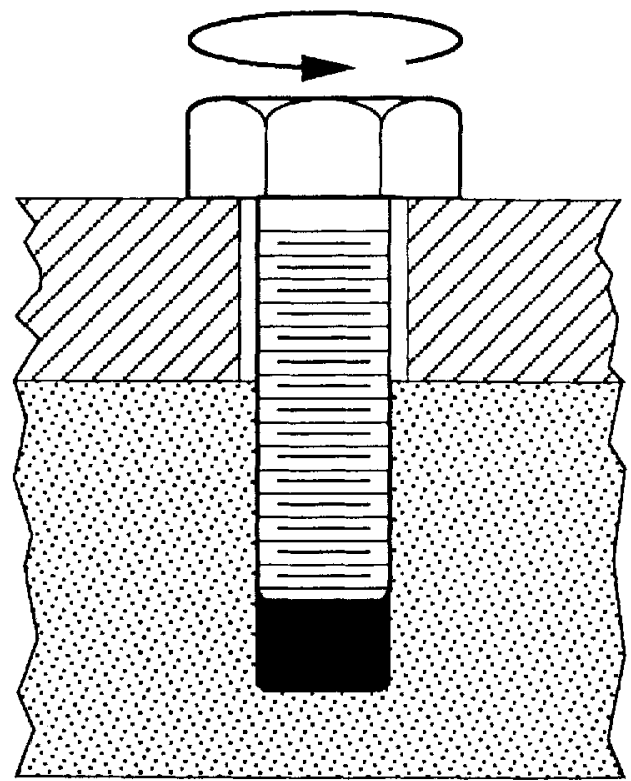

Figure 3. An example of preload tension caused by torque applied to the head of the bolt.

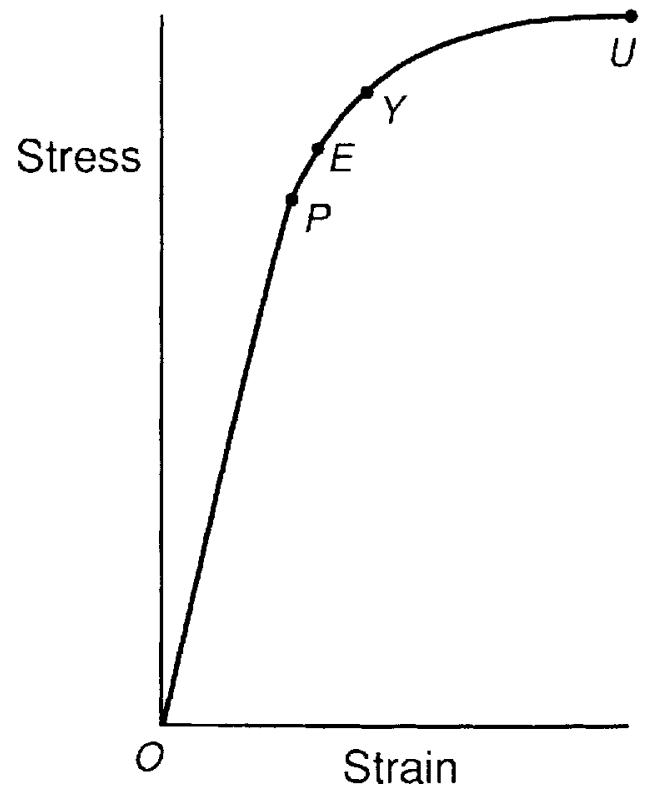

Figure 4. Stress-strain diagram. P, proportional limit; E, elastic limit; Y, yield point; $\mathbf{U}$, ultimate strength.

mum at point $\mathrm{U}$, the ultimate strength, and fracture of the screw occurs then or soon after.

In most industrial applications, the recommended preload for bolts and screws is $75 \%$ of the yield strength. ${ }^{6}$ The yield point of a bolt or screw is not an easy number to determine; thus, the ultimate strength or fracture point is commonly used rather than the yield strength. In dental implant component usage, the clinician is faced with the same problems found in the industrial applications: there is an absence of yield-strength data. Thus, the clinician must rely on the ultimate strength data when looking at the relative merits of implant-retaining screws and the amount of preload that should be applied. This statement does not mean that the ultimate strength data can be substituted into $75 \%$ yield-strength formula to achieve the correct preload torque. If this mistake is made, then the preload values will be significantly high, and the screw may be loaded near the fracture point.

It is impossible to determine from the present study alone the optimal preload that should be placed on the various retaining screws. Although it can be safely stated that the original $10-\mathrm{Ncm}$ recommendation based on the ultimate yield strength of the Nobelpharma USA gold retaining screw is probably not applicable to the studied "look-alike" retaining screws. A basic principle of preload tension is that a high preload is very desirable; a second guideline in the design of screws and fasteners is that a properly designed bolt will either fracture during tightening 
or not at all. ${ }^{6}$ Based on these principles, the preload can be appropriately adjusted only if the clinician knows the exact yield strength of the various components that will be used and the application in which they will be used.

The findings of this study are significant in that they indicate the lack of standardization between "look-alike" components. Interchanging components has the potential to overload other components of the system. If past clinical research is used as an indicator of future success, all components of the system must remain constant. If components are interchanged, predictions regarding success rates are no longer valid.

Lastly, the clinician who ultimately must decide the preload torque for each patient, must keep in mind the concept of reliability versus validity when reviewing all of the research data. Reliability refers to an instrument or the researcher's ability to produce measurements consistently. Validity refers to an instrument or the researcher's ability to measure a phenomena accurately. ${ }^{7}$ These terms are often used interchangeably but they are very different. Reliability concerns the consistency of the measurement; it is not concerned with whether the measurement is truly indicative of the phenomena the researcher wants to measure. An improperly calibrated instrument may give consistent but invalid data. Likewise, a researcher may have consistent and accurate data, but the conclusions may be invalid because the phenomena measured was not indicative of the problem. The clinician deluged by the claims and recommendations of researchers and manufacturers can begin to decipher the available data by keeping these two criteria in mind.

\section{Conclusions}

In regards to the preload torque that the test implant prosthetic retaining screws were able to withstand before fracture, the following was found:
1. The 3i Implant Innovations gold screw was not significantly different from the Nobelpharma USA gold screw.

2. The $3 \mathrm{i}$ Implant Innovations titanium screw was able to withstand significantly less preload torque than the Nobelpharma USA gold screw.

3. The Impla-Med gold screw was able to withstand significantly less preload torque than the Nobelpharma USA gold screw.

4. The Implant Support Systems titanium screw was able to withstand significantly more preload torque than the Nobelpharma USA gold, the 3i Implant Innovations gold, the $3 \mathrm{i}$ Implant Innovations titanium, and the Impla-Med gold screws.

5. The $3 \mathrm{i}$ Implant Innovations titanium and the Impla-Med gold screws were not significantly different from each other.

\section{References}

1. Lang BR, McGlumphy $\mathrm{E}$, Lewis $\mathrm{S}$, et al: JOMI current issues forum what scicntific proof does the restorative clinician have that intersystem implant hardware components are interchangeable without potential harm to long-term survival? Int J Oral Maxillofac Implants 1993;8: 105- I I 5

2. Jaarda MJ, Razzoog ME, Gratton DG: Providing optimum torque to implant prostheses: A pilot study. Implant Dent $1993 ; 2: 5052$

3. Rangert B, Gunne J, Sullivan DY: Mechanical aspects of a Brånemark implant connected to a natural tooth: An in vitro study. Int J Oral Maxillofac Implants 1991;6:177-186

4. McGlumphy EA, Elfers CL, Mendal DA: A Comparison of torsional ductile fracture in implant coronal screws (special issue, Abstract 72).J Dent Res 1992;71:114

5. Nobclpharma Product Catalog. XXX, Sweden, Nobel Industries, 1991

6. Shigley JE, Mischke CR: The design of screws, fasteners, and connections, in: Mechanical Engineering Design, (ed 5). New York, NY, McGraw-Hill, 1989, pp 325-381

7. Marks RG: Designing a Research Projcct the Basics of Biomedical Research Methodology. New York, NY, Van Nostrand Reinhold, 1982 